\title{
Sense of Coherence, a Worthy Factor toward Nursing Student and New Graduate Satisfaction with Nursing, Goal Setting Affinities, and Coping Tendencies (Le sens de la cohérence, un facteur déterminant de la satisfaction des étudiantes et des diplômées de leur carrière en sciences infirmières, de leur propension à établir des objectifs et à trouver des mécanismes de coping)
}

Shannon Dames

Vancouver Island University, shannon.dames@viu.ca

Stephen Javorski

Vancouver Island University, stephen.javorski@viu.ca

\section{Recommended Citation}

Dames, Shannon and Javorski, Stephen (2018) "Sense of Coherence, a Worthy Factor toward Nursing Student and New Graduate Satisfaction with Nursing, Goal Setting Affinities, and Coping Tendencies (Le sens de la cohérence, un facteur déterminant de la satisfaction des étudiantes et des diplômées de leur carrière en sciences infirmières, de leur propension à établir des objectifs et à trouver des mécanismes de coping)," Quality Advancement in Nursing Education - Avancées en formation infirmière: Vol. 4: Iss. 1, Article 3.

DOI: https://doi.org/10.17483/2368-6669.1108

This Article is brought to you for free and open access by Quality Advancement in Nursing Education - Avancées en formation infirmière. It has been accepted for inclusion in Quality Advancement in Nursing Education - Avancées en formation infirmière by an authorized editor of Quality Advancement in Nursing Education - Avancées en formation infirmière. 


\section{Introduction}

\section{Contextual Background}

Nursing education is poised for many future challenges as we collectively work towards preparing leaders of Canada's health care. Capable leaders are required to face the challenges of an often-tumultuous health care environment. A proactive approach to teaching nursing students how to increase their sense of coherence (Antonovsky, 1987) results in a greater confidence to manage stressors and to feel meaningfully engaged in their work. Ultimately, this process will aid in improving the health of nurses and the progression of the nursing profession. A sense of coherence is the extent to which the stimuli derived from his or her environment in the course of living is framed, predictable, and explainable and that resources are available to meet the event's demands and that these demands are considered worthy of their engagement (Antonovsky, 1987).

The health care environment is wrought with stressors as novice nurses struggle to complete tasks with which they are not yet comfortable while feeling the need to prove their worth to senior nurses (Griffin, 2004). Anxiety is often masked with a smiling face to avoid being singled out amongst the more experienced nursing team (Lively, 2000; Pearson \& Porath, 2012). Consecutive days of this routine, coupled with heavy workloads, put new nurses at high risk for emotional exhaustion and burnout; one in five novice nurses feel burned out with the intention of leaving the profession within five years (Rudman, Gustavsson, \& Hultell, 2014). Compounding this, those who have a lower sense of coherence are more likely to abuse substances to cope with their stress (Larm, Åslund, Starrin, \& Nilsson, 2016). The outcome of this reality is high attrition rates, and burnout is a primary factor in why new graduate nurses are leaving the profession (Suzuki et al., 2010).

Employer-sponsored programs aim to support the student to professional nurse transition, and they are commonplace in many urban hospital settings. However, despite these efforts, national attrition rates of new graduate nurses remain high (Chachula, Myrick, \& Yonge, 2015; Kovner, Fairchild, \& Poornima, 2007; Odland, Sneltvedt, \& Sorlie, 2014). Relying on employer programs to address the low satisfaction rates of novice nurses does not appear to be an adequate solution. While the concept of burnout in nursing remains underdeveloped, research suggests that stressors toward burnout may begin in the undergraduate setting. Student nurses who are already experiencing feelings of burnout are at a significantly higher risk of leaving their position after only 10 to 15 months (Rudman \& Gustavsson, 2012; Rudman et al., 2014). Workplace stressors may not be immediately changeable, but how one comes to these environments is changeable. Sense of coherence, which includes emotional awareness and management, is an important factor to adequately prepare students prior to their entry into professional practice.

\section{Sense of Coherence Background}

Antonovsky (1979) developed the concept of sense of coherence (SOC) to better understand why some people tend to maintain their emotional and physical health in stressful environments, while others do not. In Antonovsky's research, those who had lower SOC experienced more dis-ease and went on to develop physical and emotional health consequences as a result. He found that those with higher SOC tended to view stimuli from an optimistic perspective, often resolving or at least managing them before they become stressful. They have confidence that events will work out in a reasonable manner and trust that they have the necessary skills to navigate challenges as they arise (Antonovsky, 1987). 
SOC is considered a key coping resource in working through emotions, dealing with stress, and managing difficult situations (Lazarus \& Folkman, 1984). Antonovsky (1984) described general resistance resources as factors that promote SOC and act as a buffer against the negative impacts of stressful stimuli. These resources include one's feelings of financial security, social supports, and childhood experiences. Furthermore, research demonstrates that the degree of adverse childhood experiences one lives through as a child significantly and inversely impacts one's SOC score as an adult (Bruskas \& Tessin, 2013). The experience of chronic childhood adversity positively correlates with the risk of developing depression and anxiety disorders, both of which make it more difficult to identify and manage triggers when they arise in the workplace (Breslau, Chilcoat, Kessler, \& Davis, 1999; Fossion, Leys, Kempenaers, Braun, Verbanck, \& Linkowski, 2014; Green et al., 2000; Sullivan et al., 2009). Furthermore, experiencing frequent childhood adversities sensitizes individuals to stressful events later in life, which then makes them more prone to negative physical and psychological health impacts. This sensitization weakens one's SOC (Fossion et al., 2014).

Relating the aforementioned definition of SOC to nursing, it describes the novice nurse's feeling of control within their role as a nurse. Those with higher scores are more likely to find a meaningful connection to their work and an ability to habitually work through areas of psychological stress. Students with a high SOC will be better equipped to successfully transition into their professional role with hope, optimism, and confidence, which enables them to thrive despite the well-known challenges and obstacles they will encounter. Building awareness among nursing students about the risk and protective factors associated with SOC may enable students to better articulate their weakness and create a plan to buffer them. This awareness and the ability to articulate how their own life experiences enable or disable them may then provide a path toward improving their SOC prior to immersing themselves in the workplace.

SOC and age. The SOC model assists in understanding how one experiences satisfaction gains and losses as they age in their profession (Besen, Matz-Costa, Brown, Smyer, \& PittCatsouphes, 2013). Age appears to impact SOC scores in some studies, with SOC tending to be higher amongst older age groups (Eriksson \& Lindström, 2005; Merakou, Xefteri, \& Barbouni, 2016). As nurses become older, they may experience some physical and cognitive losses but gain experience and social support. While the losses may add stressors, the gains can buffer and overshadow them. Each professional, work context and individual will advance uniquely as they age in their field and will have a different experience in this balancing of assets. Self-mastery and self-esteem are qualities that often develop through time and experience, potentially making those above the age of 30 often more resilient to work environments that involve a high level of emotional stress (Erol \& Orth, 2011; Lindmark, Stenström, Wärnberg-Gerdin, \& Hugoson, 2010).

SOC and substance abuse. Lower SOC scores are linked to higher levels of using substances to cope (Larm et al., 2016). Conversely, those with higher scores tend to exercise more and choose healthier foods (Anderson \& Berg, 2001).

SOC and goal setting. Goal setting theory and social cognitive theory both agree in their acknowledgment that self-efficacy and conscious goal setting are imperative to one's likelihood of attaining their goals; this finding relates to empowered people feeling more control over their life outcomes. Bandura (1997) also suggested that they are more likely to engage in purposeful goal attainment, which reprograms their subconscious to continue creating goals, adjusting their actions to move toward attainment. In my experience as a nursing educator, developing learning 
goals around course requirements and mandated nursing competencies is a practice that nursing students take up early on in their educational journey. Students who embrace learning as an exciting venture seem to take ownership of their goals, closely aligning them to their passions within nursing. Taking ownership of their goals then promotes SOC in that it enables greater feelings of control and manageability within their career. Nel, Crafford, and Roodt (2004) found that goal setting impacts SOC scores if well supported by their supervisor, influencing the individual's belief in self and their level of empowerment to achieve meaningful goals.

SOC and burnout. SOC enables individuals to view stimuli as manageable events rather than threatening stressors. This optimistic perspective can buffer nursing students and soon-tobe-new graduates nurses from the stressors that are endemic in the work environment (Antonovsky, 1987). This perspective is important because many novice nurses are leaving the profession due to burnout (Suzuki et al., 2010) and the research suggests the stressors toward burnout may begin in the undergraduate experience (Rudman \& Gustavsson, 2012). Additionally, transition programs often focus on the first six months to a year of practice, but $47 \%$ experience a significant increase in burnout during their second year in the workforce, and one in five novice nurses felt periods of feeling burned out with the intention of leaving the profession within five years (Rudman et al., 2014).

Many of us can relate to the mental impacts that chronic stress has on our ability to think and cope effectively. What is not often discussed is the long-term physical effects it has if left unaddressed. Caring for individuals over long periods produces chronic stress related to problematic behaviours common in clinical settings (Castle, Wilkins, Heck, Tanzy, \& Fahey, 1995). These chronic stressors produce higher levels of cortisol linked to prolonged endocrine and immune dysregulation, lower vaccine responses, and delayed wound healing (Baum, Cohen, \& Hall, 1993; Kiecolt-Glaser, McGuire, Robles, \& Glaser, 2002). Studies demonstrate that working in high-stress environments, such as nursing, has notable physical consequences on both quality and quantity of life. However, according to the literature (Johnson, Cowin, Wilson, \& Young, 2012; Willetts \& Clarke, 2014), those with higher SOC and who are feeling in control and grounded, are more likely to have higher levels of satisfaction. Additionally, this same literature reports that they are more engaged in their work, they perform at higher levels of practice, they are committed, and they are more likely to maintain their physical and mental health.

The purpose of this study, which took place at a university in a western Canadian province, was to investigate the significance of SOC of nursing students preparing to enter professional practice. SOC is compared to their level of satisfaction with nursing as a career choice, age, the use of substances to cope with ongoing stress, and goal setting tendencies. These factors are relevant to nurse educators and employers as they impact the readiness of novice nurses to successfully navigate stressors that are endemic in the field of nursing. Based on the literature noted above, those who are more able to navigate stressors may be less prone to burnout early in their career.

\section{Study Aim}

The primary goal of this study was to establish whether or not significant relationships existed between a sense of coherence and age, satisfaction in nursing as a career choice, the abuse of substances to cope with stress, and goal setting tendencies. The primary research questions were: 
1. What are the relationships between age, ownership of learning goals, coping mechanisms, and sense of coherence scores?

2. How do sense of coherence scores relate to satisfaction of career choice for fourth-year students getting ready to enter into the nursing profession?

3. What do fourth-year students want to be incorporated into the nursing curriculum to better prepare them emotionally for the highly stressful new graduate work environment?

\section{Methods}

\section{Design}

This questionnaire study used a critical realist (Bhaskar, 1978) approach to establish significant quantitative relationships with SOC scores, while acknowledging constructivist principles through open-ended qualitative questions to understand how context can better promote the ability to not only survive, but also to thrive as a novice nurse. This critical realist orientation suggests that we do not create knowledge, but rather it is an "unfolding of the enfolded" (Scott \& Bhaskar, 2015, p. 33). Therefore, this study sought to identify the significance of SOC in nursing students and specifically, to uncover how it impacts satisfaction with nursing, coping tendencies, and goal setting habits. While we deductively explored relationships between factors, we also acknowledged that there were multiple interplaying factors or mechanisms (Bhaskar, 1978) that affected both SOC scores and their relationship to the study outcomes; these tensions are carefully managed.

\section{Survey Method}

The quantitative portion of the questionnaire used a widely researched and validated SOC scoring questionnaire, named the Orientation to Life Questionnaire (Antonovsky, 1984). Two versions are available, one with 29 questions and a shortened version with 13 questions. Both versions show similar validity, which was demonstrated by Antonovsky in 1993, whereby he found that, in 26 studies, using the 29-question version had an alpha measure of internal consistency that ranged from 0.82 to 0.95 , and the 13 -question version had a range from 0.74 to 0.91 (Antonovsky, 1993). Numerous other studies have since used the 13-question version, further validating its effectiveness (Eriksson \& Lindström, 2005). Based on these results and to honour the participant's time, we used the 13-question version. The SOC-13 scale represents the three SOC components, which are comprehensibility (questions 2, 6, 8, 9, 11), manageability (questions 3, 5, 10, 13), and meaningfulness (questions 1, 4, 7, 12). The response choices are rated on a 7-point Likert scale. Participants cannot self-score, which is made clear on the consent form because five of the questions are reverse-scored.

To identify which factors are significant in relationship to SOC, three additional quantitative questions were asked regarding the participants' satisfaction in nursing as a career choice, regular coping habits, and their affinity toward formal goal setting. Finally, three qualitative questions were asked to gain student perspectives and suggestions regarding ownership of learning goals, self-awareness, and coping skill development opportunities within the undergraduate and the new graduate employer setting. 


\section{Participants}

All fourth-year BSN students were invited to participate with 51 out of the total class of 72 students completing the anonymous questionnaire.

\section{Data Collection}

Data collection occurred on the final day of their classes at the completion of their fourth and final year in April 2016. Students were instructed to complete the 13-question Orientation to Life Questionnaire and, in addition, to choose one answer for each of the below questions:

- How satisfied are you with your choice of nursing as a career?

○ Very Satisfied

- Ambiguous at times, but mostly satisfied

○ Questioning my fit in nursing regularly

- Do you see yourself continuing to write goals, monitor them, and evaluate your success when you are practicing as a professional nurse (without the academic obligation)?

- Yes or No

- Do you use food/drugs/alcohol to cope with your stress 3 or more days a week?

○ Yes or No

Following each of the above questions were two open-ended questions:

1. In what ways have you found the nursing curriculum has developed your orientation to life? (Questions in the previous survey elude to the meaning of this) e.g., Concepts around... activities focusing on....

2. In what ways could the curriculum more explicitly work on developing more coherence within your orientation to life? e.g., More awareness around...., Using an existing tool in a different way....

\section{Analysis}

The 51 questionnaires were analyzed with SPSS software for the quantitative components, using correlations, one-way ANOVA, and ordinary least squares regression to evaluate relationships between variables. Assumptions of these models were met. The qualitative portions aimed to garner student curriculum recommendations, which were manually analyzed via categorical coding for response trends (Merriam, 2014).

\section{Ethical Considerations}

The hosting institution's research ethics board approved the study. We adhered to the conditions of approval throughout the research process. Information about the voluntary nature of participation, including the option to decline participation without explanation was provided within the informed consent. Finally, a dual role conflict was considered with the researcher also performing the role of an acting faculty member at the host institution. This conflict was anticipated and managed via an anonymous process, incorporating a third party to obtain the surveys and by withholding the research results from being viewed until after final grades were submitted. The surveys were completed on the last day of classes, whereby students had 
completed all of their course requirements to graduate. Furthermore, students were asked to return their survey whether they completed it or not to a drop box; this ensured an additional level of confidentiality in that returning surveys to the drop box did not indicate whether they were filled out or not. Additionally, the informed consent form, attached to the survey, instructed them to not indicate their names on the survey to protect their anonymity. A third party then kept the drop box until final grades were posted.

\section{Quantitative Results}

\section{Descriptives}

A total of 51 undergraduates in the fourth year of a BSN program participated in this study. The average age of participants was 25.0 years $(S D=4.3$ years) and the mean sense of coherence score was 58.8 ( $S D=10.8)$, with possible SOC scores ranging from 13 to 91 (Antonovksy, 1987).

Fifty-two percent of participants reported that they did not use food, drugs, or alcohol to manage stress while $48 \%$ did use these coping mechanisms. The majority of the sample $(63.8 \%)$ reported they did intend to continue setting goals after graduation, while the majority of students $(88.0 \%)$ were mostly or very satisfied with their choice to be a professional nurse.

\section{Study Question One - What are the relationships between age, ownership of learning goals, coping mechanisms, and sense of coherence scores?}

Significant correlations. Correlations were performed in order to evaluate study question one (see Table 1). A moderate negative relationship was found between using food, alcohol, or drugs to cope with stress and coherence score $(r=-.38, p=.008)$. Age was positively correlated with an intent to continue setting goals following graduation $(r=.476, p=.001)$.

Table 1

Correlations between SOC scale score, age, coping tendencies, and affinities toward continuing goal setting

\begin{tabular}{lcccc}
\hline & 1 & 2 & 3 & 4 \\
\hline $\begin{array}{l}(1) \text { Total Score } \\
(n=49)\end{array}$ & - & .190 & $-.378^{* *}$ & .215 \\
$\begin{array}{l}(2) \text { Age } \\
(n=47)\end{array}$ & - & -.067 & $.476^{*}$ \\
(3) Unhealthy & & & \\
Coping $(n=48)$ & & - & -.225 \\
$(4)$ Goals & & & \\
$(n=45)$ & & & - \\
$* p<.05, * * p<.01$ & & &
\end{tabular}

Insignificant correlations. As illustrated in Table 1, age and SOC scores had a weak correlation, but it was not significant $(r=.19, p=.2)$. Age and using food, alcohol, or drugs to cope were not significantly correlated $(r=-.067, p=.65)$, nor were SOC scores and an intent to continue to set goals after graduation $(r=.22, p=.16)$. 
To further evaluate study question one, a regression model was created to predict a coherence score using age, unhealthy coping strategies, and intention to continue with goal setting following graduation (see Table 2$)$. The overall model was significant $\left(F_{(3,39)}=3.26\right.$, $p=0.032)$, and unhealthy coping $(B=-7.79, p=.018)$ was the only significant predictor of the coherence score, controlling for all other variables in the model. On average, using food, drugs, or alcohol to cope with stress was associated with a -7.79-point difference in coherence score. Age, coping strategies, and intention to continue with goal setting accounted for $20.5 \%$ of the variance in SOC score $\left(R^{2}=.205\right)$.

\begin{tabular}{lcccc}
\hline IV's & $\boldsymbol{B}$ & $\boldsymbol{S}$ & $\boldsymbol{t}$ & $\boldsymbol{p}$ \\
\hline Intercept & 53.43 & 9.231 & 5.79 & $<.001$ \\
Age & .315 & .391 & .806 & .426 \\
Unhealthy cope & -7.79 & 3.13 & -2.48 & .018 \\
Continue goals & 2.60 & 3.76 & .691 & .494 \\
\hline$R^{2}=.21$ & & & \\
$F=3.23$ & & & & \\
$S S_{r}=3774.93$ & & & & \\
$S S_{l}=4745.64$ & & & & \\
\hline
\end{tabular}

Table 2

Predictors of SOC in undergraduate nursing students

\section{Study Question Two - Level of Satisfaction with Nursing}

A one-way ANOVA was conducted to evaluate study question two (see Table 3). There was a significant relationship between satisfaction with nursing and coherence scores $\left(\mathrm{F}_{(2,45)}=4.98, p=.011\right)$. Equal variances were assumed $\left(L S_{(2,45)}=1.17, p=.32\right)$, and Bonferoni's post hoc was used to assess relationships between levels of satisfaction with nursing and coherence scores. One significant relationship was found: on average, students who reported being very satisfied with nursing as a career choice had mean coherence scores $(M=62.97, S D=8.10) 14.8$ points higher than those who regularly questioned their fit in nursing $(M=48.17, S D=12.31$, $\mathrm{p}=.009$ ). In total, an estimated 14.2 percent of the variance in student coherence scores can be accounted for by satisfaction with nursing $\left(\omega^{2}=.142\right)$.

Table 3

ANOVA results comparing mean SOC score by satisfaction with nursing

\begin{tabular}{lccccc}
\hline & $\boldsymbol{S S}$ & $\boldsymbol{d} \boldsymbol{f}$ & $\boldsymbol{M S}$ & $\boldsymbol{F}$ & $\boldsymbol{p}$ \\
\hline Between Groups & 1019.03 & 2 & 509.51 & 4.98 & .011 \\
Within Groups & 4602.29 & 45 & 102.27 & & \\
Total & 5621.31 & 47 & & & \\
\hline
\end{tabular}


In summary, the quantitative research results showed that older students were more likely to value goal setting and those regularly using substances to cope with stress were more likely to have a lower sense of coherence scores. Additionally, being very satisfied with nursing as a career choice was associated with greater SOC scores.

\section{Qualitative Results}

The responses to the open-ended questions were coded based on the nature of the suggested improvements. These are illustrated in Tables 4 and Table 5.

Table 4

Coded qualitative data toward developing self-awareness and coping skills in nursing curriculum

\begin{tabular}{|c|c|c|}
\hline Qualitative Response Trends & \# & Response Examples \\
\hline \multirow{3}{*}{$\begin{array}{l}\text { Make self-care practice a } \\
\text { more visible priority in the } \\
\text { delivery of the curriculum by } \\
\text { providing time to } \\
\text { accommodate it and more } \\
\text { time to reflect and debrief } \\
\text { about it }\end{array}$} & \multirow[t]{3}{*}{9} & Decrease workload to allow for more time to cope. \\
\hline & & $\begin{array}{l}\text { More discussion and support of positive coping } \\
\text { mechanisms and self-care. }\end{array}$ \\
\hline & & $\begin{array}{l}\text { More coping time/planning for more reasonable and } \\
\text { helpful debriefing. }\end{array}$ \\
\hline \multirow{4}{*}{$\begin{array}{l}\text { Providing more education } \\
\text { about burnout prevention and } \\
\text { coping skills }\end{array}$} & \multirow[t]{4}{*}{8} & $\begin{array}{l}\text { Developing skills already present. Helping us acknowledge } \\
\text { coping skills already present with us. }\end{array}$ \\
\hline & & $\begin{array}{l}\text { The curriculum could speak more to realistic nursing } \\
\text { situations rather than the "ideal" or "airy/fairy" situations. } \\
\text { Students could then have more appropriate expectations } \\
\text { and realize the norm and prepare emotionally and mentally } \\
\text { for certain scenarios. }\end{array}$ \\
\hline & & $\begin{array}{l}\text { Teaching self-care. Personality tests, understanding self. } \\
\text { Cautions of burnout and chronic stress. }\end{array}$ \\
\hline & & $\begin{array}{l}\text { Creating an awareness of burnout/risks associated with } \\
\text { new nurses early on and continuously through the program. }\end{array}$ \\
\hline \multirow{5}{*}{$\begin{array}{l}\text { Making sense of coherence a } \\
\text { formally recognized } \\
\text { competency }\end{array}$} & \multirow[t]{5}{*}{5} & $\begin{array}{l}\text { Mandatory reporting of what you are doing for self- } \\
\text { care/maintaining fitness to practice. }\end{array}$ \\
\hline & & Make us identify our coping strategies. \\
\hline & & $\begin{array}{l}\text { If nursing has such a high turnover, why aren't we taught } \\
\text { about how to keep ourselves in check? }\end{array}$ \\
\hline & & Don't just tell us what they are; teach us how to do it. \\
\hline & & $\begin{array}{l}\text { Training is required in emotional intelligence and coping } \\
\text { skills. }\end{array}$ \\
\hline $\begin{array}{l}\text { Training around conflict and } \\
\text { bullying management }\end{array}$ & 3 & $\begin{array}{l}\text { It would be nice if the route of the problem that leads to } \\
\text { bullying and burnout could be addressed = workload. I } \\
\text { think many nurses bully because they are burnt out from }\end{array}$ \\
\hline
\end{tabular}


stress of workload. These are the preceptors who pressure students to take on larger assignments than are appropriate and the cycle continues. Students need to be encouraged to seek help and know that this isn't admission of incompetence or weakness. I was bullied for an entire practicum in third year due to the power differential and fear to admit this was happening.

Guidance and teaching about managing conflict and horizontal bullying.

Faculty role-modeling of respectful ways of being with each other, not perpetuating "power over" relations
2 Creating a more open environment with less power over (from instructors) to actually open up.

Note. The column labeled "\#” refers to the number of coded responses displaying similar response trends.

Table 5

Coded qualitative data toward relevancy and motivation of goal setting in nursing curriculum

\begin{tabular}{lll}
\hline $\begin{array}{l}\text { Qualitative Response Trends } \\
\text { Make goals come from the } \\
\text { student, owned and wanted, } \\
\text { not obligatory }\end{array}$ & $\begin{array}{l}\text { Response Examples } \\
\text { Mere emphasis on where we want to be rather than where } \\
\text { we have to be. } \\
\text { Explain [goals] as a HUMAN instead of a nurse. }\end{array}$ \\
\hline $\begin{array}{l}\text { Recognize alternative ways } \\
\text { of goal setting, writing goals } \\
\text { down formally is not the only } \\
\text { way to have and achieve } \\
\text { goals }\end{array}$ & $\begin{array}{l}\text { More freedom in method of creating and submitting goals } \\
\text { and reflections. }\end{array}$ \\
\hline $\begin{array}{l}\text { Less volume of goals, fewer, } \\
\text { more focused goals seems } \\
\text { more achievable. More time } \\
\text { to make goals }\end{array}$ & 3 & $\begin{array}{l}\text { Encourage them to set one goal per week; it feels more } \\
\text { attainable and less overwhelming. }\end{array}$ \\
\hline $\begin{array}{l}\text { More focus on formal goals } \\
\text { and their benefits in the } \\
\text { curriculum }\end{array}$ & 2 & $\begin{array}{l}\text { Perhaps students would take more initiative in their goal } \\
\text { setting if they could somehow see the benefits of this } \\
\text { practice. } \\
\text { Better explanation in first year would be helpful. }\end{array}$ \\
\hline
\end{tabular}

Note. The column labeled "\#” refers to the number of coded responses displaying similar response trends. 
In order of frequency, the qualitative responses that students suggest promoting development of self-awareness and effective coping include: (1) more time to integrate self-care practice and incorporation of self-care activities into their reflective assignments; (2) providing more education about burnout prevention and coping skills; (3) making sense of coherence/resilience/emotional intelligence a formally recognized competency; (4) training around conflict and bullying management; and (4) faculty role-modeling of respectful ways of being with each other, not perpetuating "power over" relations.

In order of frequency, the qualitative responses that students suggest to promote goal setting relevancy include: (1) explore ways to encourage authentic goal-setting, whereby goals are authentic to the student as opposed to an obligational assignment; (2) recognize alternative ways of goal setting, writing goals down formally is not the only way to have and achieve goals; (3) allow for fewer and more focused goals; and (4) more education on the benefits of goals setting to promote motivation and ownership.

\section{Discussion}

The most prominent findings in this study, which are noted above, were as follows:

1. The development of SOC enables stimuli to be navigated, which may prevent them from becoming a stressor. Those who have or develop SOC in nursing school may be more satisfied in their nursing role and less prone to burnout and substance abuse as they enter their nursing careers.

2. Students who are younger in age may not value formal goal setting as readily as older students. In this study, there is a desire for more flexibility in the process with more focus on authentic goal setting, as opposed to a process that feels prescribed to them by others.

Now, these key findings will be discussed in relation to the literature.

\section{SOC and Satisfaction with Nursing}

As presented in the results section above, there is a positive association between SOC and satisfaction with nursing as a career choice amongst the fourth-year BSN student participants. In other words, the mean SOC score for people who were very satisfied with nursing was significantly higher than the mean SOC scores of those who regularly question their fit in nursing. This finding supports the notion that those who are more satisfied in nursing tend to have a higher SOC. The qualities of these higher SOC scores include a greater ability to navigate stressors and to find meaning in work tasks, and a greater tendency toward an optimistic orientation (Antonovsky, 1987). Relating this to nursing, those who have a higher SOC will be driven by a sense of meaning and control over their environment and have the confidence to work through practice setting stressors. Conversely, those with lower SOC scores may feel less control over their environment, find less meaning in their role as a nurse, and feel less confident to work through stressors. Thereby, those who are more satisfied with nursing as a career choice come into their new graduate careers with a greater ability to manage stressors and find meaning in their work, reducing their desire to leave their job and their risk of burnout. This finding aligns with other studies in the literature, whereby SOC positively correlates with overall satisfaction with life (Ando, 2016; Moksnes, Lohre, \& Espnes, 2013). 


\section{SOC, Age, and Goal Setting}

In this study, age was significant in relation to goal setting, but not in relation to satisfaction with nursing as a career choice or a SOC. As for SOC, satisfaction with nursing and age, given that only 5 out of the 51 survey respondents were 30 or older, may not have been a reliable measurement. In larger studies, older participants tended to have higher SOC scores, whereby age positively correlates with higher SOC scores (Eriksson \& Lindström, 2005; Merakou et al., 2016). Essentially, life experience enables nursing students to acquire resources that can bolster their SOC, which Antonovsky (1987) refers to as "general resistance resources".

As for age and goal setting, in this study, age positively correlated with a sense of value for formal goal setting and intention to set goals entering their nursing career. According to the literature, those older in age tend to have higher SOC scores (Eriksson \& Lindström, 2005; Merakou et al., 2016) and thereby they may be more likely to view goals optimistically and to ensure goals are authentic to their desires. These findings have implications for nursing educators and employers, enabling a targeted approach and taking age into consideration for their student and employee needs. For instance, those who are younger and those who have a lower SOC may struggle to differentiate between goals that they desire and those that others have prescribed for them. Promoting ownership of goals may require an articulation of this struggle and a more pointed exploration process to ensure that goals feel authentic and worthy of engagement, which then promotes goal achievement (Antonovsky, 1987; Bandura, 1997). This difficulty may explain why formal goal setting feels more obligational for many of the participants. To be specific, there are numerous comments in the qualitative results that goals feel obligatory. Trends in the data suggest that goals be more authentic and personalized to promote ownership through greater flexibility in the process of setting goals and education about the benefits. These findings align with the literature, which underscores the necessity that goals feel authentic to the goal setter (Bandura, 1997), rather than as a token assignment. Nurse educators can promote flexibility, allowing students to cater the process to their preferences, thereby promoting a greater sense of ownership of the process.

\section{Substance Abuse to Cope with Stress}

Nearly half of the participants in this study reported that they abuse substances to cope with their stress three or more days a week. In addition, there was a significant correlation between substance use and lower SOC scores. These results align with Antonovsky's (1987) SOC concept in that those with lower SOC scores feel less control over their life and have less confidence in their ability to manage stressors. It also aligns with studies that demonstrate that those with lower SOC may be more prone to living with psychological stress leading to a compulsion to find reprieve from the stress through distractive coping tendencies (Anderson \& Berg, 2001; Larm et al., 2016). This finding is significant in that those with lower scores are at a higher risk of health and mental health consequences directly related to substance abuse. These risks have implications for nursing students, educators, and employers. Being informed about these risks can help students enhance their SOC, which may then lower their risk of using substances to cope with stress.

\section{Opportunities to Empower Students in the Undergraduate-nursing Curriculum}

Qualitative responses demonstrated that the nursing students wanted to improve their emotional management skill; they advocated for more curriculum components that could better support their development. Additionally, personal development factors that enabled the ability to 
resolve or at least manage stressors promote the confidence to manage stimuli before they become stressors, which ultimately improves SOC. These findings align with Antonovsky's (1987) definition of SOC, which is defined above.

While the nursing curriculum may explicitly address emotional management and respectful relations, students in this study desired more interweaving into the cultural ways. For example, these areas could be implicitly demonstrated via faculty modeling, reflective assignments, and clinical mentorship. Additionally, articulating moments whereby opportunities arise to address hostility from faculty and senior nurses, whereby "power over" relations occur. According to the literature, adding a more explicit curriculum, which occurs by adding assignments, policies, etc., does not effectively alter cultural ways of being (Bain, 1990; Hooper, 2008). However, an implicit curriculum is highly effective at impacting these components (Bain, 1990; Hooper, 2008). An implicit curriculum includes program culture, customs, rituals, and how people relate to one another. Essentially, this process translates into working with faculty to establish a culture that promotes authentic and respectful relationships via role modeling, perhaps exploring areas where students may feel vulnerable within the power hierarchy. Perhaps there are also opportunities to have a greater focus on the emotions that emerge as they work through their dissonance in clinical settings, which promotes emotional awareness and the habit of debriefing when dissonance arises.

\section{Summary of the Literature and Implications}

This study is novel in its use of SOC as an independent variable in relation to satisfaction with nursing, the curriculum, and coping tendencies of fourth-year nursing students who are on the threshold of entry into professional practice. The findings align with other literature sources, whereby SOC scores are predictive of one's tendency towards an optimistic life orientation (Ando, 2016; Moksnes et al., 2013) or, in this case, one's optimistic orientation toward nursing. Additionally, those with higher scores were less likely to abuse substances to cope with stress, which also aligns with our literature findings (Larm et al., 2016). In this study, being older correlated positively with valuing formal goal setting. According to the literature, older nurses may have a higher SOC and a greater ability to articulate authentic goals, which may promote ownership and appreciation for the investing in the goal setting process (Eriksson \& Lindström, 2005; Merakou et al., 2016).

Results are relevant to nursing students, undergraduate nurse educators, and administrators of new graduate nurse transition programs. Nurse educators can prepare students for practice readiness by way of skill development in authentic ways of being, emotional readiness, and ownership over their own SOC and career goals. It underscores a desire for more self-awareness and confidence building to promote management of psychological stress and contextual stressors within the undergraduate curriculum. Furthermore, these same needs flow into employer-sponsored transition programs, which may provide higher levels of fulfillment in nursing and result in lower levels of substance abuse, burnout, and staff turnover.

\section{Limitations and Recommendations}

The quantitative portion of the study is limited by the sample size of 51 participants from which to draw correlations. However, the response rate was over 50\%, and, thereby, it is a reliable representation of the total student cohort of 72 . Furthermore, the age range is limited by the majority falling into the mid- to late-20s age category, with few students over the age of 30 . Demographically, the study only represents one university's cohort of students thereby it is 
difficult to generalize to nursing students that may fall under a different curriculum or cultural setting. Furthermore, regarding substance abuse to cope with stress, the survey grouped food, alcohol, and drugs together and did not elaborate on them independently. Future research could assess each substance independently. Despite these limitations, the literature supports the findings, relating SOC to a reduction in substance abuse to cope with stressors and a more optimistic orientation and satisfaction with one's life.

\section{Conclusion}

This study adds to the current literature, supporting a sense of coherence (SOC) as a predictive factor of nursing students' sense of control and meaning making in their life, which in turn produces a greater sense of fulfillment and confidence in their future as a professional nurse. Understanding SOC as an important satisfaction factor can inform nurse educators and curriculum development efforts. Nursing students with lower SOC scores can be informed that they may be at higher risk of burnout and substance abuse when under stress, and they can have a chance prior to practice entry to work on their emotional readiness for the field. If nurses enter into practice with a higher SOC and thereby levels of confidence and satisfaction in nursing, they may stand a better chance of surviving and even thriving as new graduate nurses. Furthermore, goal setting relates to one's building of self-efficacy (Bandura, 1997); therefore, developing an environment in which the value of this habit is clear and novice nurses feel ownership over their goals will promote self-efficacy and provide feelings of empowerment and control to fulfill their professional aspirations. 


\section{References}

Andersen, S., \& Berg, J. E. (2001). The use of a sense of coherence test to predict drop-out and mortality after residential treatment of substance abuse. Addiction Research \& Theory, 9(3), 239-251. https://doi.org/10.3109/16066350109141752

Ando, M. (2016, August). Relationships among moral distress, sense of coherence, and job satisfaction. Nursing Ethics. https://doi.org/10.1177/0969733016660882

Antonovsky, A. (1979). Health, Stress and Coping. San Francisco, CA: Jossey-Bass.

Antonovsky, A. (1984). The sense of coherence as a determinant of health. In J. D. Matarazzo, S. M. Weiss, J. A. Herd, N. E. Miller, \& S. M. Weiss (Eds.), Behavioral health: A handbook of health enhancement and disease prevention (pp. 114-129). New York, NY: John Wiley \& Sons.

Antonovsky, A. (1987). Unraveling the Mystery of Health: How people manage stress and stay well. San Francisco, CA: Jossey-Bass.

Antonovsky, A. (1993). The structure and properties of the sense of coherence scale. Social Science \& Medicine, 36(6), 725-733. https://doi.org/10.1016/0277-9536(93)90033-z

Bain, L. L. (1990). A critical analysis of the hidden curriculum in physical education. In D. Kirk \& R. Tinning (Eds.), Physical education, curriculum, and culture: Critical issues in the contemporary crisis (pp. 19-34). London, UK: The Farmer Press.

Bandura, A. (1997). Self-efficacy: The exercise of control. New York, NY: Freeman.

Baum, A., Cohen, L., \& Hall, M. (1993). Control and intrusive memories as possible determinants of chronic stress. Psychosomatic Medicine, 55, 274-286. https://doi.org/10.1097/00006842-199305000-00005

Besen, E., Matz-Costa, C., Brown, M., Smyer, M. A., \& Pitt-Catsouphes, M. (2013). Job characteristics, core self-evaluations, and job satisfaction: What's age got to do with it? The International Journal of Aging and Human Development, 76(4), 269-295. https://doi.org/10.2190/ag.76.4.a

Bhaskar, R. (1978). A realist theory of science. Hemel Hempstead, UK: Harvester Press.

Bruskas, D., \& Tessin, D. H. (2013). Adverse childhood experiences and psychosocial wellbeing of women who were in foster care as children. The Permanente Journal, 17(3), e131-e141. https://doi.org/10.7812/tpp/12-121

Castle, S., Wilkins, S., Heck, E., Tanzy, K., \& Fahey, J. (1995). Depression in caregivers of demented patients is associated with altered immunity: Impaired proliferative capacity, increased CD8, and a decline in lymphocytes with surface signal transduction molecules (CD38) and a cytotoxicity marker (CD56 CD8). Clinical and Experimental Immunology, 101, 487-493. https://doi.org/10.1111/j.1365-2249.1995.tb03139.x

Chachula, K. M., Myrick, F., \& Yonge, O. (2015). Letting go: How newly graduated registered nurses in western Canada decide to exit the nursing profession. Nurse Education Today, 35(7), 912-918. https://doi.org/10.1016/j.nedt.2015.02.024

Eriksson, M., \& Lindström, B. (2005). Validity of Antonovsky's sense of coherence scale: A systematic review. Journal of Epidemiology and Community Health, 59(6), 460-466. 
https://doi.org/10.1136/jech.2003.018085

Erol, R. Y., \& Orth, U. (2011). Self-esteem development from age 14 to 30 years: A longitudinal study. Journal of Personality and Social Psychology, 101(3), 607-619. https://doi.org/10.1037/a0024299

Fossion, P., Leys, C., Kempenaers, C., Braun, S., Verbanck, P., \& Linkowski, P. (2014). Disentangling sense of coherence and resilience in case of multiple traumas. Journal of Affective Disorders, 21(6), 21-26. https://doi.org/10.1016/j.jad.2014.02.029

Green, B. L., Goodman, L. A., Krupnick, J. L., Corcoran, C. B., Petty, R. M., Stockton, P., \& Stern, N. M. (2000). Outcomes of single versus multiple trauma exposure in a screening sample. Journal of Traumatic Stress, 13(2), 271-286. https://doi.org/10.1023/a:1007758711939

Griffin, M. (2004). Teaching cognitive rehearsal as a shield for lateral violence: An intervention for newly licensed nurses. Journal of Continuing Education in Nursing, 35(6), 257.

Hooper, B. (2008). Stories we teach by: Intersections among faculty biography, student formation, and instructional processes. American Journal of Occupational Therapy, 62(2), 228-241. https://doi.org/10.5014/ajot.62.2.228

Johnson, M., Cowin, L. S., Wilson, I., \& Young, H. (2012). Professional identity and nursing: contemporary theoretical developments and future research challenges. International Nursing Review, 59(4), 562-569. https://doi.org/10.1111/j.1466-7657.2012.01013.x

Kiecolt-Glaser, J. K., McGuire, L., Robles, T. F., \& Glaser, R. (2002). Psychoneuroimmunology: Psychological influences on immune function and health. Journal of Consulting and Clinical Psychology, 70(3), 537-547. https://doi.org/10.1037//0022-006x.70.3.537

Kovner, C., Fairchild, S., \& Poornima, H. (2007). Newly licensed RNs' characteristics, work attitudes, and intentions to work. The American Journal of Nursing, 107(9), 58-70. https://doi.org/10.1097/01.naj.0000287512.31006.66

Larm, P., Åslund, C., Starrin, B., \& Nilsson, K. W. (2016). How are social capital and sense of coherence associated with hazardous alcohol use? Findings from a large population-based Swedish sample of adults. Scandinavian Journal of Public Health, 44(5), 525-533. https://doi.org/10.1177/1403494816645221

Lazarus, R., \& Folkman, S. (1984). Stress, Appraisal, and Coping. New York, NY: Springer.

Lindmark, U., Stenström, U., Wärnberg-Gerdin, E., \& Hugoson, A. (2010). The distribution of "sense of coherence" among Swedish adults: A quantitative cross-sectional population study. Scandinavian Journal of Public Health, 38(1), 1-8. https://doi.org/10.1177/1403494809351654

Lively, K. J. (2000). Reciprocal emotion management: Working together to maintain stratification in private law firms. Work and Occupations, 27(1), 32-63. https://doi.org/10.1177/0730888400027001003

Merakou, K., Xefteri, E., \& Barbouni, A. (2016). Sense of coherence in religious christian orthodox women in Greece. Community Mental Health Journal, 1-5. https://doi.org/10.1007/s10597-016-0051-1 
Merriam, S. B. (2014). Qualitative research: A guide to design and implementation (3rd ed.). Hoboken, NJ: Wiley.

Moksnes, U. K., Lohre, A., \& Espnes, G. A. (2013). The association between sense of coherence and life satisfaction in adolescents. Quality of Life Research, 22(6), 1331-1338. https://doi.org/10.1007/s11136-012-0249-9

Nel, D., Crafford, A., \& Roodt, G. (2004). The relationship between sense of coherence and goal setting. SA Journal of Industrial Psychology, 30(2), 46-55. https://doi.org/10.4102/sajip.v30i2.154

Odland, L-V., Sneltvedt, T. \& Sorlie, V. (2014). Responsible but unprepared: Experiences of newly educated nurses in hospital care. Nurse Education in Practice, 14(5), 538-543. https://doi.org/10.1016/j.nepr.2014.05.005

Porath, C. L., \& Pearson, C. M. (2012). Emotional and behavioral responses to workplace incivility and the impact of hierarchical status. Journal of Applied Social Psychology, 42, 326-357. https://doi.org/10.1111/j.1559-1816.2012.01020.x

Rudman, A., \& Gustavsson, J. P. (2012). Burnout during nursing education predicts lower occupational preparedness and future clinical performance: A longitudinal study.

International Journal of Nursing Studies, 49(8), 988-1001. https://doi.org/10.1016/j.ijnurstu.2012.03.010

Rudman, A., Gustavsson, J. P., \& Hultell, D. (2014). A Prospective study of nurses' intentions to leave the profession during their first five years of practice in Sweden. International Journal Nursing Studies, 51(4), 612-624. https://doi.org/10.1016/j.ijnurstu.2013.09.012

Scott, D., \& Bhaskar, R. (2015). Roy Bhaskar: A theory of education. Cham, Switzerland: Springer International Publishing.

Sullivan, S., Mkabile, S. G., Fincham, D. S., Ahmed R., Stein D. J., \& Seedat, S. (2009). The cumulative effect of multiple trauma on symptoms of posttraumatic stress disorder, anxiety, and depression in adolescents. Comprehensive Psychiatry, 50(2), 121-127. https://doi.org/10.1016/j.comppsych.2008.06.006

Suzuki, E., Tagaya, A., Ota, K., Nagasawa, Y., Matsuura, R., \& Sato, C. (2010). Factors affecting turnover of Japanese novice nurses in university hospitals in early and later years of employment. Journal of Nursing Management, 18(2), 194-204. https://doi.org/10.1111/j.1365-2834.2010.01054.x

Willetts, G., \& Clarke, D. (2014). Constructing nurses' professional identity through social identity theory. International Journal of Nursing Practice, 20(9), 164-169. https://doi.org/10.1111/ijn.12108 